\title{
Maternal and perinatal outcome in a pregnancy with nephrotic syndrome
}

\author{
Vineet Mishra $^{1 *}$, Himani Agarwal ${ }^{1}$, Sunita Lamba ${ }^{1}$, Sumesh Chaudhary $^{1}$, \\ Priyankur Roy ${ }^{2}$, Sugandha Goel ${ }^{1}$
}

\begin{abstract}
${ }^{1}$ Department of Obstetrics and Gynecology, IKDRC-ITS, Ahmedabad, Gujrat, India
${ }^{2}$ Department of Obstetrics and Gynecology, NBMCH, Siliguri, West Bengal, India
\end{abstract}

Received: 29 March 2017

Accepted: 27 April 2017

\section{*Correspondence:}

Dr. Vineet Mishra,

E-mail: vineet.mishra.ikdrc@gmail.com

Copyright: (c) the author(s), publisher and licensee Medip Academy. This is an open-access article distributed under the terms of the Creative Commons Attribution Non-Commercial License, which permits unrestricted non-commercial use, distribution, and reproduction in any medium, provided the original work is properly cited.

\begin{abstract}
The influence of pregnancy on the subsequent course of pre-existing nephrotic syndrome is controversial as also the effect of membranous glomerulonephritis on maternal and perinatal outcome. We describe a case of successful pregnancy outcome in Hepatitis B reactive patient with pre-existing nephrotic syndrome (renal biopsy proven case of Membrano-proliferative Glomerulonephritis). She had regular nephrology consultation and her renal disease was well compensated. After sonographic confirmation of live intrauterine pregnancy at 9th gestational week, patient was given methylprednisolone ( $5 \mathrm{mg}$ once daily). Antihypertensive drugs were also given. At 35 weeks of gestation, patient went in labour and cesarean section was performed in view of previous caesarean section. Feto-maternal outcome was good. The intrapartum and postpartum period was uneventful. Renal functions were well preserved. A vigourous healthy $1.93 \mathrm{~kg}$ baby was discharged with mother in a stable condition after receiving hepatitis B immunoglobulin.
\end{abstract}

Keywords: Feto-maternal outcome, Membrano-proliferative glomerulonephritis, Methylprednisolone, Nephrotic syndrome, Pregnancy

\section{INTRODUCTION}

Proteinuria in pregnancy is not very uncommon. It ranges from mild elevation to gross proteinuria. ${ }^{1}$ Nephrotic range proteinuria encountered during early weeks of pregnancy does not mean preeclampsia rather it is suggestive of underlying native renal disorder. The course of pregnancy and maternal and perinatal outcome in women with pre-existing glomerulonephritis is still controversial. In many non-compliant pregnant women with pre-existing nephrotic syndrome, termination of pregnancy is recommended in view of severe deterioration of renal functions and poor feto-maternal outcome. Prompt diagnosis, adequate counselling and systematic management can lead to successful pregnancy outcome. Here we describe a case of multidisciplinary approach for managing a pregnancy in a patient with preexisting nephrotic syndrome, renal biopsy proven membrano-proliferative glomerulonephritis (MPGN) and its subsequent good feto-maternal outcome.

\section{CASE REPORT}

A 25-year-old, G2P1L1A0, with one previous caesarean section, came to the Gynaecology OPD of our tertiary care centre with positive urine pregnancy test in the period of lactational amenorrhea. Transvaginal sonography revealed single live intrauterine gestation of 9 weeks. She was dwarf and a follow up case of preexisting nephrotic syndrome due to renal biopsy proven 
MPGN on electron microscopy and immunofluorescence. Patient was diagnosed as a case of nephrotic syndrome at the age of 5 years and was started on Tab Methylprednisolone $5 \mathrm{mg}$ once daily, Tab Tacrolimus 0.5 $\mathrm{mg}$ once daily and Tab Mycophenolatemofetil $250 \mathrm{mg}$ twice daily. These medications were continued for 2 years and subsequently stopped after nephrologist opinion.

She conceived in drug compliance period (Tab Methylprednisolone $10 \mathrm{mg}$ once daily) and had regular nephrology consultation. Thorough investigations unraveled well compensated renal disease. IgG antiphospholipid antibodies, serum C3, C4, ANA, antids-DNA, total serum IgG and IgA levels, IgM cardiolipin antibodies were normal. She was found to be Hepatitis B reactive, other viral markers and HBV-DNA were normal. She was prescribed Tab Methylprednisolone (10mg once daily). Antihypertensive drugs were also given. Frequent follow up with laboratory investigations was done. Renal function test (serum creatinine 1.6 $\mathrm{mg} / \mathrm{dl}$ ) and 24 hours' urinary protein $(2300 \mathrm{mg} / 24$ hours $)$ were serially monitored.

Calibration of steroid therapy was done according to 24 hours' urine protein excretion and Tab Methylprednisolone was tapered to $5 \mathrm{mg}$ once daily. Proper antepartum fetal monitoring to rule out IUGR was done. Her previous pregnancy was also uncomplicated. Severe anaemia (Hb-6.2gm \%) was detected at 33 weeks of pregnancy and correction was done with blood component therapy. At 35 weeks of gestational age, patient went in labour and cesarean section was performed in view of previous caesarean section. Her intrapartum and postpartum period was uneventful. Renal functions were well preserved. A healthy $1.93 \mathrm{~kg}$ baby was discharged with mother in a stable condition after receiving hepatitis $\mathrm{B}$ immunoglobulin. Tab Methylprednisolone $5 \mathrm{mg}$ once daily was continued. Stitch removal was done on $8^{\text {th }}$ postoperative day and she was advised to follow-up regularly.

\section{DISCUSSION}

Pregnancy with nephrotic syndrome (NS) is very rare. The co-existence of both of these conditions is reported to vary from 0.012 to $0.025 \%$. The relative frequency of occurrence of nephrotic syndrome during childbearing period is very uncommon and is assumed to be due to obstacles in conception caused by any serious chronic illness. $^{2}$

In most non-pregnant adults with NS, primary sodium retention by the kidneys leads to vascular overfilling, possibly from activation of the epithelial sodium channel by serine proteases. ${ }^{3}$ The hemodynamic effects of NS on pregnancy are not well described. Packham et al. concluded that pregnant women with MPGN is often associated with an increased risk of fetal loss and also worsening of maternal renal functions. ${ }^{4}$
Pregnancy and nephrotic syndrome, both are hypercoagulable states. In our case, the gestational age at presentation was 9 weeks, consistent with previous observation that proteinuria before 20 weeks' gestation is suggestive of primary kidney disease rather than preeclampsia. Due to coexistence and also because of difficulty in differentiating nephrotic syndrome from preeclampsia, the relative incidence of nephrotic syndrome secondary to underlying glomerular dysfunction is uncertain without a histologic renal biopsy report. Renal biopsy confirms the underlying etiology. Super-speciality consultation plays a key role in proper management.

Frequent follow up with laboratory investigations is mandatory. Renal function tests and 24 hours' urinary protein should be serially monitored. Elevated creatinine is an established risk factor for adverse pregnancy outcomes. ${ }^{5}$ In our patient, the serum creatinine was 1.6 $\mathrm{mg} / \mathrm{dl}$ and 24 hours' urinary protein was $2300 \mathrm{mg} / 24$ hours. Other studies have described the critical role of renal function as it relates to outcomes in pregnancy. ${ }^{6}$

In our case, there was no association between adverse feto-maternal outcome and a history of hypertension, although our patient had heavy proteinuria (2300mg/24hours). Various studies have previously reported direct association of proteinuria with adverse feto-maternal outcome. Packham et al. evaluated 33 pregnancies in women with membranous nephropathy and found that proteinuria was the only predictor of a poor maternal and fetal outcome4. Park et al. described 62 pregnancies with lupus nephritis and found that proteinuria $>0.5 \mathrm{~g} / \mathrm{d}$ was associated with adverse outcomes. ${ }^{7}$ Liu et al. showed a similar association between proteinuria and adverse pregnancy outcomes in their cohort with IgA nephropathy. ${ }^{8}$

Steroid therapy is the mainstay of treatment. Steroids were most commonly chosen to treat the glomerular lesions. Steroids are generally safe during pregnancy. Prednisone does not represent a major teratogenic risk in humans at therapeutic doses. ${ }^{9}$ Calibration of steroid therapy is done according to 24 hours' urine protein excretion. Treatment with steroids is often found to be associated with obstetric complications like IUGR, PROM and other infections. Concerns include worsening maternal glucose and BP control, premature rupture of membranes, and infection. ${ }^{10}$ In our case, there was no documented derangement in maternal blood sugar levels and not any worsening of blood pressure after steroid therapy. Early detection of IUGR through proper antepartum fetal monitoring is recommended.

Spontaneous labour at term is favoured. Caesarean section is performed for obstetric indications only. Spontaneous resolution in post-partum period occurs in most of the cases. However, long term follow up is done on the basis of 24 hours' urinary protein excretion. Prolonged steroids are required in unresolved cases. The presence of NS due to renal disease, in the absence of 
significant renal insufficiency or hypertension, has been described to have minimal effects on the natural course of renal disease or maternal-fetal outcomes. ${ }^{11}$ In our case also, in the absence of uncontrolled hypertension and renal insufficiency, the perinatal outcome in pregnant women with nephrotic syndrome was found to be good.

\section{CONCLUSION}

Pre-conceptional counselling and baseline investigations plays a pivotal role in any pregnancy associated with renal disorders. Continuation of pregnancy should be planned when renal functions are well preserved and along with regular nephrologist consultation. Early diagnosis, adequate counselling, multidisciplinary approach and judicious management with specific therapy can lead to good feto-maternal outcome in a pregnant woman with pre-existing nephrotic syndrome.

Funding: No funding sources Conflict of interest: None declared

Ethical approval: Not required

\section{REFERENCES}

1. Kincaid-Smith P, Fairley KF. The differential diagnosis between pre-eclamptic toxemia and glomerulonephritis in patients with proteinuria during pregnancy. Perspect Nephrol Hypertens. 1976;5:157-67.

2. Cohen AW, Burton HG. Nephrotic syndrome due to pre-eclamptic nephropathy in a hydatidiform mole and coexistent fetus. Obstet Gynaecol. 1979;53:1304.

3. Jungers $P$, Houillier $P$, Forget D. Influence of pregnancy on the course of primary chronic glomerulonephritis. Lancet. 1995;346:1122-4.
4. Packham DK, North RA, Fairley KF, Whitworth JA, Kincaid-Smith P. Membranous glomerulonephritis and pregnancy. Clin Nephrol. 1987;28:56-64.

5. Hayslett JP, Reece EA. Managing diabetic patients with nephropathy and other vascular complications. Baillieres Clin Obstet Gynaecol. 1994;8:405-24.

6. Nevis IF, Reitsma A, Dominic A. Pregnancy outcomes in women with chronic kidney disease: A systematic review. Clin J Am Soc Nephrol. 2011;6: 2587-98.

7. Park EJ, Jung H, Hwang J. Pregnancy outcomes in patients with systemic lupus erythematosus: A retrospective review of 62 pregnancies at a single tertiary center in South Korea. Int J Rheum Dis. 2014; 17:887-97.

8. Liu Y, Ma X, Lv J. Risk factors for pregnancy outcomes in patients with IgA nephropathy: A matched cohort study. Am J Kidney Dis. 2014;64: 730-6.

9. Park-Wyllie L, Mazzotta P, Pastuszak A. Birth defects after maternal exposure to corticosteroids: Prospective cohort study and meta-analysis of epidemiological studies. Teratology. 2000;62:38592.

10. Guller S, Kong L, Wozniak R. Reduction of extracellular matrix protein expression in human amnion epithelial cells by glucocorticoids: a potential role in preterm rupture of the fetal membranes. J Clin Endocrinol Metab. 1995;80:2244-50.

11. Studd JW, Blainey JD. Pregnancy and the nephrotic syndrome. BMJ. 1969;1:276-80.

Cite this article as: Mishra V, Agarwal H, Lamba S, Chaudhary S, Roy P, Goel S. Maternal and perinatal outcome in a pregnancy with nephrotic syndrome. Int J Reprod Contracept Obstet Gynecol 2017;6:2657-9. 